\title{
Effect of Photobiomodulation Therapy on Oxidative Stress Markers in Healing Dynamics of Diabetic Neuropathic Wounds in Wistar Rats
}

\author{
Gagana Karkada ${ }^{1} \cdot$ G. Arun Maiya $\mathbb{C}^{2} \cdot{\text { Praveen } \text { Arany }^{3} \cdot \text { Mohandas Rao }^{4} \cdot \text { Shalini Adiga }}^{5} \cdot$ Shobha Ullas Kamath $^{6}$
}

Accepted: 3 July 2021 / Published online: 30 July 2021

(c) The Author(s) 2021

\begin{abstract}
Background Prolonged and overlapping phases of wound healing in diabetes are mainly due to the redox imbalance resulting in the chronicity of the wound. Photobiomodulation therapy works on the principle of absorption of photon energy and its transduction into a biological response in the living tissue. It alleviates the cellular responses, thereby improving the mechanism of wound healing in diabetes.

Objective To find out the effect of photobiomodulation therapy of dosage $4 \mathrm{~J} / \mathrm{cm}^{2}$ in the healing dynamics of diabetic neuropathic wounds in Wistar rats and its relation with oxidative stress markers.

Methodology Diabetes was induced using Streptozotocin of $60 \mathrm{mg} / \mathrm{kg}$ of body weight to eighteen female Wistar rats. Neuropathy was induced by the sciatic nerve crush injury followed by an excisional wound of $2 \mathrm{~cm}^{2}$ on the back of the animal. Experimental group animals were treated with dosage $4 \mathrm{~J} / \mathrm{cm}^{2}$ of wavelength 655 and $808 \mathrm{~nm}$, and control group animals were kept unirradiated. The biomechanical, histopathological, and biochemical changes were analysed in both groups.

Results There was a reduction in mean wound healing time and an increased rate of wound contraction in the experimental group animals compared to its control group. The experimental group showed improved redox status, and histopathological findings revealed better proliferative cells, keratinisation, and epithelialization than un-irradiated controls.

Conclusions Photobiomodulation therapy of dosage $4 \mathrm{~J} / \mathrm{cm}^{2}$ enhanced the overall wound healing dynamics of the diabetesinduced neuropathic wound and optimised the oxidative status of the wound, thereby facilitating a faster healing process.
\end{abstract}

Keywords Diabetic wounds $\cdot$ Catalase $\cdot$ Malondialdehyde $\cdot$ Oxidative stress $\cdot$ Photobiomodulation therapy $\cdot$ Wound healing

G. Arun Maiya

arun.maiya@manipal.edu

1 Scholar, Centre for Diabetic Foot Care and Research (CDFCR), Department of Physiotherapy, Manipal College of Health Professions, Manipal Academy of Higher Education, Manipal, Karnataka 576104, India

2 Chief-Centre for Diabetic Foot Care and Research (CDFCR), Professor-Department of Physiotherapy, Dean-Manipal College of Health Professions (MCHP), Manipal Academy of Higher Education, Manipal, Karnataka 576104, India

3 Department of Oral Biology School of Dental Medicine, Engineering \& Applied Sciences, University at Buffalo., 3435 Main Street, B36A, Foster Hall, Buffalo, NY 14214-8031, USA

4 Head of the Department-Department of Anatomy, Melaka Manipal Medical College-Manipal Campus, Manipal Academy of Higher Education, Manipal, Karnataka 576104, India

5 Head of the Department, Department of Pharmacology, Kasturba Medical College, Manipal Academy of Higher Education, Manipal, Karnataka 576104, India

6 Department of Biochemistry, Kasturba Medical College, Manipal Academy of Higher Education, Manipal, Karnataka 576104, India

\begin{tabular}{ll}
\multicolumn{2}{l}{ Abbreviations } \\
ATP & adenosine triphosphate \\
DFU & diabetic foot ulcer \\
DM & diabetes mellitus \\
DPN & diabetic peripheral neuropathy \\
LLLT & low-level laser therapy \\
MDA & malondialdehyde \\
PBMT & photobiomodulation Therapy \\
ROS & reactive oxygen species \\
STZ & streptozotocin
\end{tabular}

\section{Introduction}

Diabetes mellitus (DM) is a leading non-communicable disease in India and Globally. Individuals with DM suffer from microvascular and macrovascular complications that predispose them to develop conditions like cardiovascular diseases, peripheral vascular diseases, retinopathy, nephropathy, and peripheral neuropathy [1]. Diabetic foot ulcer (DFU) is the most complex yet neglected complication of diabetic peripheral 
neuropathy (DPN). The intrinsic and extrinsic factors of DPN makes the feet vulnerable to injuries and tissue damage, causing chronic wound or ulcer [2]. The global burden of DM affected nearly 463 million people in 2019 and is anticipated to rise up to 700 million by the end of 2045. During the 2019 survey, India reported the prevalence of 72 million people affected by DM and an anticipated increase of up to 153 million by 2045 . Globally, foot ulcers occur in 15-25\% of people with DM and between $5-7.5 \%$ of those with neuropathy [3].

Delayed wound healing in DM is a major secondary complication that often ends with the loss of limb and disability. Regular wound repair progresses through the discrete phases of inflammatory, proliferative, and remodelling. In $\mathrm{DM}$, these phases are prolonged and overlapped due to underlying excessive tissue damage, tissue perfusion, and lack of oxygenation that delay the wound healing process [4]. The tissue renewal process depends on the level of oxygen $\left(\mathrm{O}_{2}\right)$ at the wound bed. The fundamental cellular process where oxygen is involved in the oxidative phosphorylation in mitochondria, mainly yields adenosine triphosphates (ATPs). The derivatives of $\mathrm{O}_{2}$, known as reactive oxygen species (ROS) produced during mitochondrial ATP production, act as signalling molecules in tissue repair. The low-level ROS results in cell cycle arrest, increased levels result in oxidative damage and cell apoptosis. Therefore, the optimum levels of ROS molecules are required for the normal tissue repair process [5]. The homoeostasis of ROS molecules generated during wound healing is by the special group of molecules known as antioxidants. These antioxidants have the capacity to significantly delay or prevent oxidative action of ROS and mitigate its deleterious effects. The well-known antioxidants are glutathione, superoxide dismutase, and catalase etc. [6].

Catalases are the haem containing antioxidant enzyme mainly produced in nuclear peroxisomes and mitochondria that catalytically decompose Hydrogen peroxide $\left(\mathrm{H}_{2} \mathrm{O}_{2}\right)$ into oxygen and water using iron and manganese as cofactors. It can reduce the concentration of $\mathrm{H}_{2} \mathrm{O}_{2}$ at a rapid rate without consuming cellular energy, thereby providing cell defence against oxidative damage. However, in diabetic wound healing, catalase activity is decreased, leading to increased $\mathrm{H}_{2} \mathrm{O}_{2}$ concentrations in the blood and tissues $[7,8]$. The failure of redox balance at the wound site results in delayed cellular responses, failing the wound recovery.

Photobiomodulation therapy (PBMT) is a promising conservative non-pharmacological approach in the management of diabetic wound healing. PBMT works on the principle of low energy biostimulation, causing photochemical reactions in the cells/tissue [9]. Studies have explored the effectiveness of PBMT in diabetic wound healing in vitro, in vivo, where PBMT of dosage $2-6 \mathrm{~J} / \mathrm{cm}^{2}$ had shown a beneficial effect in wound healing dynamics [10-12]. PBMT is believed to alter enzyme activation and cell cycle progression, thereby affecting cells' redox- sensitive transcription factors. PBMT enhances antioxidants production by enzymatic reactions, which are the fundamental mechanisms involved in wound healing [13].

Although there are studies involving the mechanism of PBMT in wound healing, very few studies have elucidated the dose-dependent mechanism of PBMT and their relation with oxidative markers in the healing dynamics of diabetic neuropathic wounds. Therefore the present study aims to find out the effect of PBMT of dosage $4 \mathrm{~J} / \mathrm{cm}^{2}$ in the healing dynamics of diabetes-induced neuropathic wounds in Wistar rats, with biomechanical, histopathological, and biochemical finding which may add substantial evidence to the existing literature of wound healing in diabetes.

\section{Material and Methods}

\section{Animal Selection and Care}

We obtained the institutional animal ethics committee approval before the study's initiation (IAEC/KMC/95/2018). In house bread, eighteen female Albino Wistar strain rats of weight $(220.78 \pm 11.87) \mathrm{g}$ and age $(5.43 \pm 0.11)$ months were procured from the institutional central animal research facility. The animals were housed in propylene cages $(29 \times 22 \times 14 \mathrm{~cm})$ with paddy husk bedding. Their living environment was maintained with temperature $28 \pm 1^{\circ} \mathrm{C}$, humidity $55 \pm 5 \%$, and $12 \mathrm{~h}$ of light and dark cycle. The animals were provided with sufficient food once in the day and water ad libitum.

\section{Induction of Diabetes}

Baseline blood glucose levels were measured using calibrated Accu-check Performa Nano glucometer (Roche diagnostics India). Diabetes was induced to all the animals by intraperitoneal injection of Streptozotocin (STZ) (MP Biomedical ${ }^{\mathrm{TM}}$ India) of dosage $60 \mathrm{mg} / \mathrm{kg}$ body weight dissolved in $0.1 \mathrm{M}$ citrate buffer of $\mathrm{pH} 4.5(1 \mathrm{~mL})$ [14]. Food and water were provided after $30 \mathrm{~min}$ of injection. Further, the animals were placed in individual metabolic cages to observe clinical and behavioural changes of DM for seven days.

\section{Confirmation of Diabetes}

The animals were observed for polydipsia, polyphagia, and polyuria, and changes were recorded. Besides, the weight of the animals was recorded on alternative days. On the 7th day, blood was drawn in the fasting state from the intraorbital plexus by inserting a capillary. Blood $(1.5 \mathrm{~mL})$ was drawn into the test tube containing sodium fluoride. The sample was mixed thoroughly and allowed to clot for $20 \mathrm{~min}$. The sample was then centrifuged at $2000 \times g$ for $10 \mathrm{~min}$, and the supernatant serum was collected. Blood 
glucose levels were estimated using the glucose-oxidase and peroxidase method (GOD-POD kit, Coral clinical systems India). Animals with fasting blood glucose levels of $\geq 200 \mathrm{mg} / \mathrm{dL}$ were included in the study. Blood glucose levels were monitored periodically using calibrated Accucheck Performa Nano glucometer.

\section{Induction of Neuropathy by Sciatic Nerve Injury}

We followed previously established protocols developed for the neuropathic model in all the animals $[15,16]$. Under expert supervision, the animals were anaesthetised with intravenous Ketamine of dosage $2 \mathrm{mg} / \mathrm{kg}$ body weight. The right/left hind leg from the knee to the hip was shaved using an electric shaver. An incision was made $\sim 0.5 \mathrm{~cm}$ parallel to the femur and about $1.5 \mathrm{~mm}$ anterior to the femur. Under sterile conditions, the sciatic nerve was revealed until midthigh level and crushed for $20 \mathrm{~s}$ with the tip of watchman forceps $(2 \times 15 \mathrm{~s})$ to induce neuropathy.

\section{Confirmation of Neuropathy}

The animals were kept for three weeks of the stabilisation period. Their clinical and behavioural changes for neuropathy were recorded. The walking, scratching, grooming, resting/sleeping, eating, and freezing activities were observed. The following tests were performed to confirm the neuropathy in the feet.

\subsection{7 monofilament $(10 \mathrm{~g})$ test}

Semmes Weinstein $10 \mathrm{gm}$ monofilament is used in human participants for the detection of loss of protective sensation. A slightly modified procedure was performed on the animal's feet [17]. Here, the animals were placed on a metal mesh grid. Monofilament was applied perpendicularly with a force of $10 \mathrm{~g}$ from the lower surface of the mesh to the plantar areas of the hind paws. The time taken in seconds by the animals to withdraw paw in response to monofilament touch was noted. In the normal feet, The time taken for the paw withdrawal was between 1-4 s, whereas the neuropathy induced feet showed a delayed response.

\section{Hind paw withdrawal test for hot stimulus}

We followed the previously established procedure for hind paw withdrawal to confirm the neuropathy [16]. The animals were placed on a metal hot plate $\left(45 \pm 0.5^{\circ} \mathrm{C}\right)$ of dimensions $15 \times 15 \mathrm{~cm}$ for an evaluation period of $3 \mathrm{~min}$. The total duration for responding to the hot stimulus by each animal to lift neuropathy induced and non-induced leg was noted. In the non-induced feet, The time taken for the paw withdrawal was between 1 and $4 \mathrm{~s}$, whereas the neuropathy induced feet showed a delayed response.
Hind paw withdrawal test for cold stimulus using acetone

The slightly modified procedure from the previous study was conducted [18]. The animal was placed upon a metal mesh grid with open access to the paws from below. A cotton swab was dipped in acetone and was brought into the plantar surface of the hind feet. The time taken to withdraw the leg from the supporting mesh after the exposure to acetone was noted. Both normal and neuropathy-induced legs were exposed to acetone, and the test was performed for $3 \mathrm{~min}$. The response within $4 \mathrm{~s}$ was considered a normal, brisk response to differentiate from the altered lifting.

On the final day of PBMT intervention, the tests were repeated to evaluate to determine the changes in their neuropathic state.

\section{Excisional Wound Model}

An excisional wound model was created on the back of the animals near the neuropathy induced leg. Animals were anaesthetised using intravenous Ketamine of $2 \mathrm{mg} / \mathrm{kg}$ body weight. The wound area to be created was marked using a circular rubber stamp of area $2 \mathrm{~cm}^{2}$ dipped in methylene blue. The dorsal fur was shaved, and an excisional wound was created along the markings using toothed forceps using number 21 surgical blade and pointed scissors [11]. The area of the wound was recorded on transparent sheets. After the procedure, each animal was kept in a separate cage, and all wounds were exposed to air.

\section{Animals Grouping}

The animals were assigned into two groups, i.e. the control and experimental groups, based on the animals' weight and blood glucose levels.

I. Control group $N=9$ (diabetic neuropathic woundedunirradiated)

II. Experimental group $N=9$ (diabetic neuropathic wounded-irradiated with $4 \mathrm{~J} / \mathrm{cm}^{2}$ )

\section{Photobiomodulation Therapy}

After calibration of the equipment Tech laser SS 100 (Technomed Electronics Chennai), the standard protocol for the laser irradiation was followed [11]. The experimental group animals were treated with PBMT of dosage $4 \mathrm{~J} / \mathrm{cm}^{2}$. A Combination of scanning and probe laser was given once a day to the experimental group animals until the complete closure of the wound ( $\sim 2$ weeks). The control group animals were kept un-irradiated. Specifications of PBMT used in the study are described in Table 1. 
Table 1 Characteristics of PBMT used in the study

\begin{tabular}{llllllll}
\hline PBM & Wavelength $(\mathrm{nm})$ & Wave emission & $\begin{array}{l}\text { Power } \\
\text { output }(\mathrm{mW})\end{array}$ & $\begin{array}{l}\text { Power Density } \\
\mathrm{mW} / \mathrm{cm}^{2}\end{array}$ & $\begin{array}{l}\text { Spot size } \\
\left(\mathrm{cm}^{2}\right)\end{array}$ & $\begin{array}{l}\text { Dosage } \mathrm{J} / \\
\mathrm{cm}^{2}\end{array}$ & Depth cm Duration min \\
\hline Scanning laser & 655 Visible red & Continuous & 24 & 2.64 & 9.1 & 4 & 1 \\
Probe laser & 808 Infra-red & Continuous & 120 & 120 & 1 & 4 & 3 \\
\hline
\end{tabular}

\section{Biomechanical Analysis of Wound}

\section{Wound area measurement}

The wound areas were recorded on a transparent sheet. The area was measured using ImageJ software (Downloaded from https://imagej.nih.gov/ij/download.html Windows Download ImageJ bundled with 64-bit Java 1.8.0_172). The total area was represented in $\mathrm{cm}^{2}$.

Mean wound healing time was calculated by taking the sum of the number of days taken for complete wound closure by each animal in the control and experimental group. Data was reported as Mean $\pm \mathrm{SD}(N=9$ in each group). Serial photographs were taken for observation of wound closure on day-1, 7 and 16 .

\section{Rate of contraction of wound}

The rate of contraction of the wound was calculated using the formula [initial area (I)-final area (F)/number of days (N)] per day $\mathrm{cm}^{2}[11]$.

\section{Histopathological analysis}

The tissues were processed on day 16th from both the experimental and the control group and

fixed in formalin (10\%) for further histopathological analysis. As per standard laboratory protocol, the tissue samples were dehydrated with ascending grades of alcohol. The samples were then transferred to Xylene to clear the remaining alcohol. The tissue was embedded and moulded in paraffin wax. The 5- $\mu$ m thick sections were obtained using a microtome, and clean sections were fixed to slides. The slides were stained with $\mathrm{H} \& \mathrm{E}$ staining to observe epithelialization and distribution of collagen fibres [19]. Each section was then viewed under the light microscope (Lx 300, Labomed, USA).

\section{Immunohistochemical analysis}

Immunohistochemistry was performed for the qualitative analysis of proliferative cells using Anti-Ki-67 antigen, Proliferating Cell [BioGenex, California], to compare the cell proliferation in the control and the experimental group. The previously established protocol was followed for immunohistochemical staining for $\mathrm{Ki}-67$ antigen-specific proliferative cells [20]. Each section was then viewed under the light microscope (Lx 300, Labomed, USA).

\section{Biochemical Analysis}

\section{Estimation of antioxidant catalase assay}

Catalase activity was determined according to Beers and Sizer by spectrophotometric monitoring of hydrogen peroxide decomposition by hemolysates at $240 \mathrm{~nm}$ at room temperature [21]. Results were expressed in units/g of haemoglobin

\section{Lipid peroxidation by malondialdehyde (MDA) assay}

MDA is a highly reactive three-carbon di-aldehyde produced as a by-product of polyunsaturated fatty acid peroxidation and arachidonic acid metabolism. Its level indicates the oxidative status of the cells. Serum MDA was measured using Kei Satoh's Method of spectrophotometric determination [22]. Results were expressed in nmol/g haemoglobin.

\section{Statistical Analysis}

Descriptive statistics were measured using EZR ( $\mathrm{R}$ version 3.4.1 (C) 2017 The R Foundation for Statistical Computing), and data were expressed in (Mean \pm SD). For the normally distributed data, Paired sample $t$-test was used. When the data were not normally distributed, the non-parametric Wilcoxon signed-rank test was used. $P<0.05$ was considered statistically significant.

\section{Results}

\section{Metabolic Cage Analysis of Diabetes-induced Animals}

Our study findings revealed that, after the induction of diabetes using STZ, all the animals showed a significant decrease $\left(p=0.015^{-6}\right)$ in their bodyweight. The weight reduction was gradual from day-1 of the induction of diabetes until day-7. There was a significant increase in the blood glucose $\left(p=0.015^{-6}\right)$, water intake $\left(p=0.081^{-6}\right)$, Urine Output $\left(p=0.039^{-6}\right)$, and food intake $\left(p=0.039^{-6}\right)$ by the end of the day- 7 . These symptoms are the classical triads of diabetes mellitus. The animals also displayed irritability, gradual hair loss, and skin colour changes upon 
diabetes induction. On day-7, the blood glucose levels of the animals were $>200 \mathrm{mg} / \mathrm{dl}$ (Fig. 1).

\section{Confirmation of Neuropathy}

There was a significant change in the paw withdrawal time in the neuropathy-induced leg compared with the non-induced leg. The recorded responses to the Monofilament test, hot stimulus, and cold stimulus in the neuropathy-induced feet are listed in Table 2. The comparison between neuropathy induced leg to that of the non-induced leg confirms the sciatic nerve's damage and affected microcirculation. The observational findings also revealed a change in their resting, walking, and scratching pattern in the neuropathy-induced leg.

\section{Biomechanical Analysis}

\section{Mean wound healing time}

The wounds were photographed to observe the healing nature on day 1, 7 and the final day of healing. The experimental group showed complete wound healing with a mean of $(16.12 \pm 0.64)$ days. The unirradiated control group showed a mean of (21.62 \pm 0.51$)$ days for complete healing (Fig. 2).

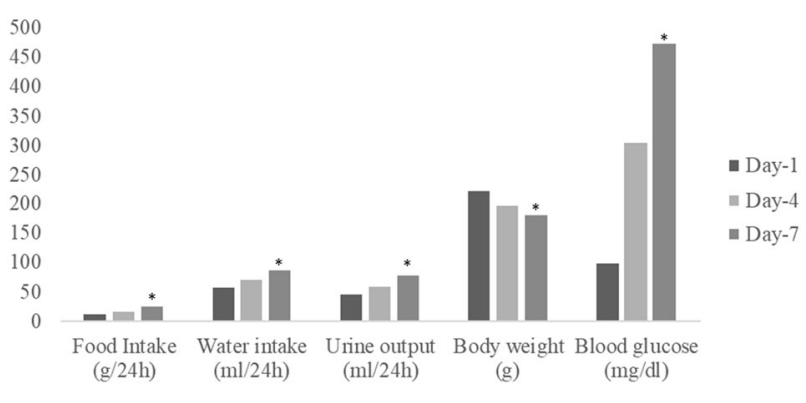

Fig. 1 Demographics and details of metabolic cage analysis of STZ induced animals $(N=18)$ ( $p$ value $<0.05$ significant $*)$. 1. Food intake (g) 2. Water intake $(\mathrm{mL}) 3$. Urine output $(\mathrm{mL}) 4$. Body weight $(\mathrm{g}) 5$. blood glucose $(\mathrm{mg} / \mathrm{dl})$.

\section{Wound contraction}

Our study's findings revealed that the wound closure was better and faster in the experimental group treated with $4 \mathrm{~J} /$ $\mathrm{cm}^{2}$ than the un-irradiated control groups. There was a significant decrease $(p=0.013)$ in mean wound healing time in the experimental group compared to the control group. The rate of wound contraction was also significantly higher in groups treated with $4 \mathrm{~J} / \mathrm{cm}^{2}(p=0.014)$ when compared to its un-irradiated controls (Table 3).

\section{Post PBMT neuropathy assessment}

The neuropathy tests performed on day 16th revealed that the experimental group animals treated with PBMT of dosage $4 \mathrm{~J} / \mathrm{cm}^{2}$ showed significant change in paw withdrawal time in the neuropathy induced feet. The response to monofilament, hot stimulus, and cold stimulus was significantly improved in neuropathy-induced feet compared to its un-irradiated control group (Table 4).

\section{Histopathological analysis}

The tissue samples were collected from the experimental group and the control group animals on day-16. The qualitative analysis of histopathology for $H \& E$ stained skin tissues from the wound area revealed a close resemblance to the normal skin. The Experimental group treated with $4 \mathrm{~J} /$ $\mathrm{cm}^{2}$ showed marked epithelialization and keratinisation, indicating a faster healing process when compared to the un-irradiated control group. (Fig. 3A, B). The density and structural organisation of collagen fibres in the dermal region showed better positioning in the experimental group when compared to that of the control group (Fig. 3C, D).

\section{Immunohistochemistry}

The experimental group and control group's immunohistochemical analysis revealed that the experimental group treated with $4 \mathrm{~J} / \mathrm{cm}^{2}$ (Fig. 4A) showed well-stained nuclei, especially in the basal layer (stratum basale) of the
Table 2 Response to neuropathy confirmation tests $(N=18)$

\begin{tabular}{lll}
\hline Confirmatory tests & $\begin{array}{l}\text { Time-taken for } \\
\text { response in sec } \\
\text { Neuropathy induced feet }\end{array}$ & $\begin{array}{l}\text { Time-taken for } \\
\text { response in sec } \\
\text { Non-induced feet }\end{array}$ \\
\hline $\begin{array}{l}\text { 1. } 10 \mathrm{~g} \text { Monofilament } \\
\begin{array}{l}\text { 2. Hind paw withdrawal test for hot stimulus } \\
\left(45 \pm 0.5^{\circ} \mathrm{C}\right)\end{array}\end{array}$ & $\begin{array}{l}7.11 \pm 1.02 \\
6.6 \pm 0.76\end{array}$ & $3.05 \pm 0.59^{*}$ \\
$\begin{array}{l}\text { 3. Hind paw withdrawal test for cold } \\
\text { stimulus using acetone }\end{array}$ & $6.22 \pm 0.7$ & $2.5 \pm 0.51^{* * *}$ \\
\hline $\begin{array}{l}\text { Values expressed in (Mean } \pm \mathrm{SD}) \\
*, * * * * * \text { represents the significant } p \text { values } 0.17^{-3}, 0.18^{-3}, 0.15^{-3} \text { respectively }\end{array}$
\end{tabular}


Fig. 2 Representative image of wound healing in experimental and control group animals. 1) Representative photographs of wound healing in experimental group in pictures 1A (Day-1), 1 B (Day-7) and 1C (Day-16) group. 2) Representative photographs of wound healing in control group in pictures $2 \mathrm{~A}$ (Day-1), 2B (Day-7) and 2C (Day-16) group

Table 3 Rate of wound contraction in the animals $(N=9$ in each group).

Table 4 Post neuropathy assessments $(N=9$ in each group).
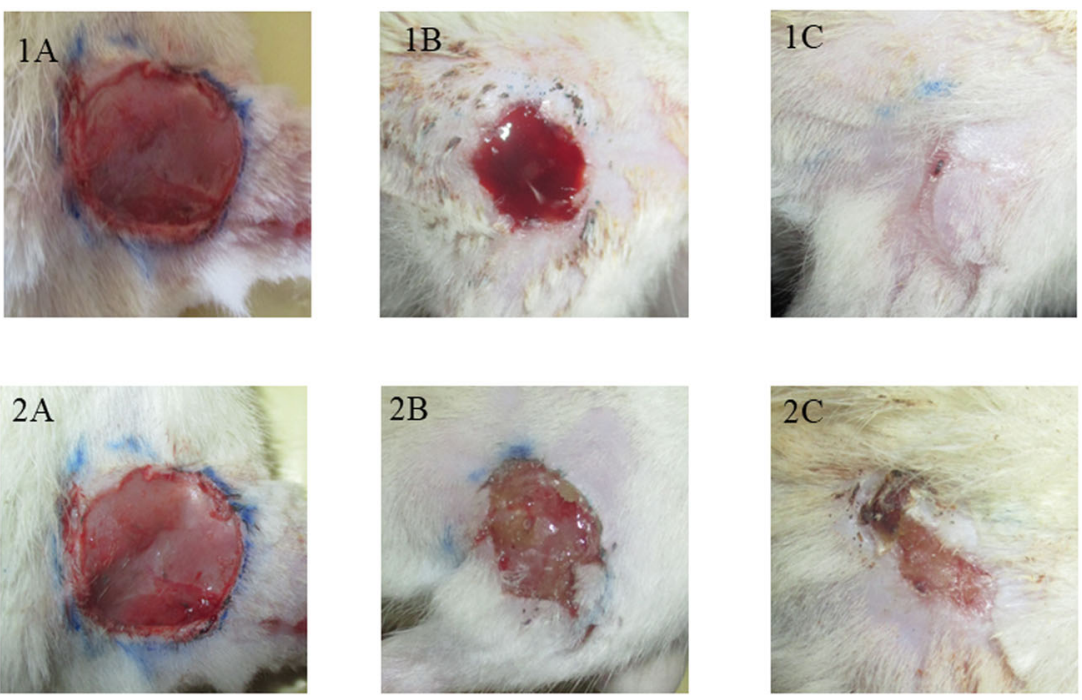

\begin{tabular}{lllll}
\hline Groups & $\begin{array}{l}\text { Initial area } \\
\left(\mathrm{cm}^{2}\right) \text { Day-1 }\end{array}$ & $\begin{array}{l}\text { Final area }\left(\mathrm{cm}^{2}\right) \\
\text { Day-16 }\end{array}$ & $\begin{array}{l}\text { Number of days for } \\
\text { healing }(\mathrm{N})\end{array}$ & $\begin{array}{l}\text { Rate of wound } \\
\text { contraction/Day }\left(\mathrm{cm}^{2}\right)\end{array}$ \\
\hline Control group & $2.0 \pm 0$ & $0.45 \pm 0.03$ & $21.62 \pm 0.51$ & $0.07 \pm 0.04$ \\
$\begin{array}{l}\text { Experimental group } \\
\left(4 \mathrm{~J} / \mathrm{cm}^{2}\right)\end{array}$ & $2.0 \pm 0$ & $0.13 \pm 0.008$ & $16.12 \pm 0.64^{*}$ & $0.11 \pm 0.13 * *$ \\
\hline
\end{tabular}

Values expressed in (Mean $\pm \mathrm{SD})$.

$*$, ** represents the significant $p$ values $0.013,0.014$, respectively

\begin{tabular}{lll}
\hline Tests & $\begin{array}{l}\text { Control group } \\
\text { Time taken response in sec } \\
\text { neuropathy induced feet }\end{array}$ & $\begin{array}{l}\text { Experimental group }\left(4 \mathrm{~J} / \mathrm{cm}^{2}\right) \\
\text { Response in sec in neuropathy } \\
\text { induced feet }\end{array}$ \\
\hline $\begin{array}{l}\text { 1. } 10 \mathrm{~g} \text { Monofilament } \\
\begin{array}{l}\text { 2. Hind paw withdrawal test for hot } \\
\text { stimulus }\left(45 \pm 0.5{ }^{\circ} \mathrm{C}\right)\end{array}\end{array}$ & $6.44 \pm 0.72$ & $6.36 \pm 0.70^{*}$ \\
$\begin{array}{l}\text { 3. Hind paw test for cold stimulus } \\
\text { using acetone }\end{array}$ & $7.00 \pm 0.78 * 0.78$ \\
\hline
\end{tabular}

Values expressed in (Mean $\pm \mathrm{SD})$

$*, * *, * * *$ represents the significant $p$ values $0.80,0.12,0.012$, respectively

epidermis indicating high proliferative activity in these cells. Besides, the abundance of active cells (fibroblasts) looked relatively high in the skin's dermal region in revealing the active production of collagen fibres compared to that of the un-irradiated control group (Fig. 4B).

\section{Catalase and MDA levels}

In the present study, we observed a significant change in the catalase and MDA levels among the group and between experimental and control group animals on day-7 and day$16(p=0.004)$. A decreased catalase activity was observed in the un-irradiated control group compared with the experimental group treated with $4 \mathrm{~J} / \mathrm{cm}^{2}$. On the contrary, we observed an increased MDA activity in control group animals compared to that of the experimental group on both day-7 and day-16 (Fig. 5).

\section{Discussion}

DM is characterised by persistent hyperglycaemia that builds up the blood vessels' sugar complexes, resulting in poor circulation and deranged nerve functions [23]. In the present study, the STZ-induced animals showed high blood glucose levels from day seven. The sciatic nerve injury to the animals demonstrated the degenerated nerve functions. The control and experimental group animals showed the 
Fig. 3 Representative photomicrographs of $\mathrm{H} \& \mathrm{E}$ staining of skin tissue of the experimental and control group.

(1) Representative

photomicrographs of $\mathrm{H} \& \mathrm{E}$

stained tissues from the wound area of experimental group treated with $4 \mathrm{~J} / \mathrm{cm}^{2}(3 \mathbf{A})$ showing better epithelialization than non-irradiated control group (3B) (marked with black arrows) under $10 x$ magnification. (2) Experimental group (3C) and control group (3D) show the collagen fibres in the dermis. $3 \mathbf{C}$ represents more organizely arranged collagen fibres when copared to 3D (marked with black circle) under 40x maginification
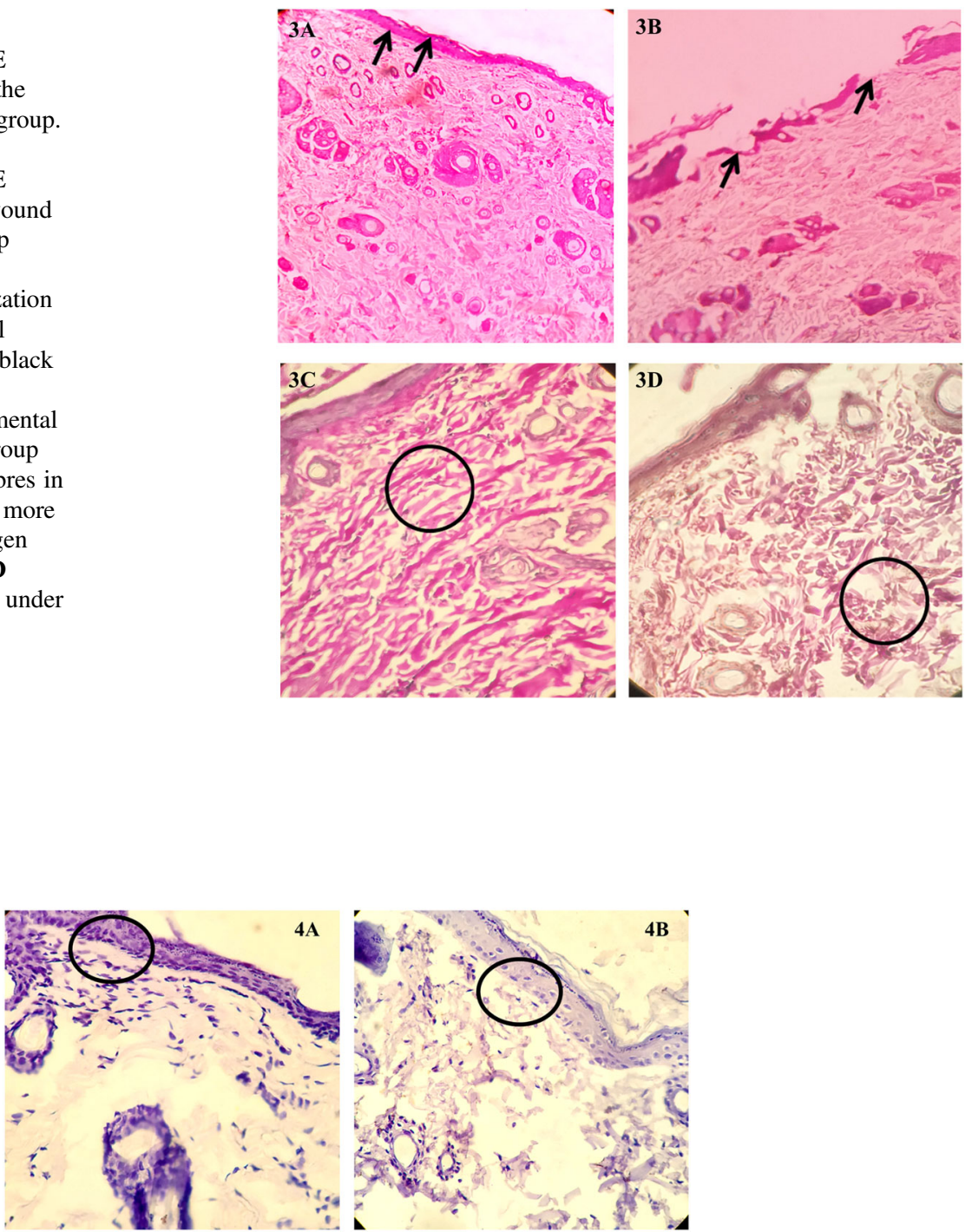

Fig. 4 Representative photomicrographs of Immunohistochemical analysis for Ki-67 antibodies for proliferative cells. Representative photomicrographs of immunohistochemical analysis of the tissues from the wound stained for IHC-Ki67 antibody for proliferative cells.

typical polydipsia, polyphagia, polyuria, and gradual weight loss symptoms of DM. Akbarzadeh et al. demonstrated these characteristics of STZ induced animals [24]. The induced STZ destructs the islets of Langerhans beta cells, and as a result, clinical diabetes emerges in the animals.

Previous studies have described the different types of mechanical peripheral nerve injury and evaluations of neuropathic pain in human and animal models using the stimuli that give the degree of mechanical, chemical, and temperature-induced changes $[17,25,26]$. In the present study, we evaluated the neuropathic changes by 5.07 Monofilament ( $10 \mathrm{~g})$ test, Hind paw withdrawal test for hot and cold stimulus where the neuropathy induced leg showed the delayed response. In Dowdall et al. study, the partial
4A Experimental group treated with $4 \mathrm{~J} / \mathrm{cm}^{2}$; $4 \mathbf{B}$ Control group. It can be noted that the experimental group showed well-stained nuclei indicating well proliferative cells especially near the stratum basale of epidermis when compared to control group (marked with black circle)

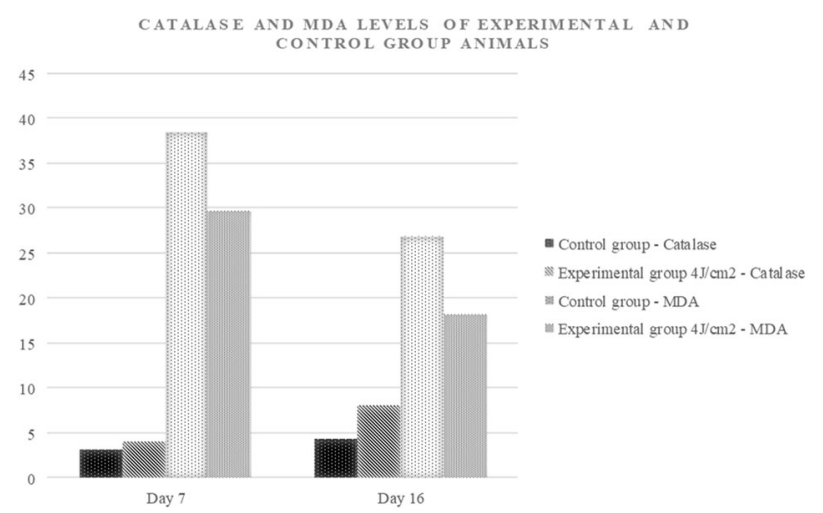

Fig. 5 Catalase and MDA levels in the experimental and control group ( $N=9$ in each group). 
sciatic nerve ligation model produced a similar and significant change in lifting behaviour on the hot plate from minimal to the absence of lifting in the neuropathy-induced leg; however, the response depends on the type of sciatic injury [18].

There is evidence for the therapeutic role of PBMT in pain management, muscle repair, and nerve damage [2729]. We also observed moderate improvements in the neuropathy-induced leg in the post-PBMT treated group compared with its control group, but the recovery was not complete. Bertolini et al. treated the animals' sciatic nerve with low-level laser therapy (LLLT) of dosage $4,6 \mathrm{~J} / \mathrm{cm}^{2}$, and $830 \mathrm{~nm}$ wavelength and found a significant change in paw-withdrawal time on the fifth day of therapy [30]. Anju et al. suggest that low-level laser therapy of dosage $3.1 \mathrm{~J} /$ $\mathrm{cm}^{2}$ significantly improved in painful diabetic neuropathy conditions [17]. PBMT can enhance the microcirculation of nerves, thereby improving the blood supply.

In the present study, the diabetic neuropathic wound models were treated with $4 \mathrm{~J} / \mathrm{cm}^{2}$ of wavelength 655 and $808 \mathrm{~nm}$ for 6 and $3 \mathrm{~min}$. The experimental group and the control group animals were kept unirradiated. We found that PBMT effectively accelerated the mean wound healing time and rate of contraction of wounds. Therefore, this significant improvement compared to the un-irradiated control group appears to be the direct effect of PBMT. Studies demonstrate the effect of PBMT of different dosages and wavelengths in chronic wound conditions like diabetic foot ulcers $[31,32]$. Maiya et al. found that LLLT of dosage 3-6 J/cm ${ }^{2}$ and wavelength $655 \mathrm{~nm}$ accelerated the wound healing with significant improvement in wound contraction rate, whereas $7-9 \mathrm{~J} / \mathrm{cm}^{2}$ decelerated the wound healing [11]. Lau et al. treated the diabetic excisional wound with LLLT of dosage $5 \mathrm{~J} / \mathrm{cm}^{2}$ and $808 \mathrm{~nm}$ but of different power densities; found that PBMT significantly enhanced the percentage of wound closure [33]. The possible mechanism could be that, the photon energy delivered to the wound tissue is absorbed and produces biostimulation, thereby enhancing cell proliferation. Cell proliferation is characterised by neovascularization, epithelialization, and granulation tissue formation in post-inflammatory phases $[9,11]$.

We have analysed the histopathological changes in the experimental and control groups to justify these results. The experimental group's H\&E stained skin tissues showed better epithelium, collagen formation, and distribution than the control group. The immunohistochemical findings revealed that the proliferative cells were present abundantly in the experimental group than the control group, representing better and faster-wound healing. Therefore, it is evident that PBMT enhanced the formation of epithelial cells, fibroblastic cells, and proliferative cells, thereby enhancing epithelial tissue, granulation tissue, and collagen.
Similar findings were also observed in Kilík et al. and Lau et al., who treated the diabetic mouse skin with PBMT $[34,35]$. However, the present study did not obtain the skin at different stages of wounding. The mechanism of PBMT in the acceleration of wound healing could be by the mild inflammatory reaction induced by the PBMT, which enhances or upregulates neo-angiogenesis and increases the blood flow around the wound. On the other hand, the capacity of the PBMT to prevent harmful reactions during the inflammatory phase, facilitating collagen formation, might have improved wound healing [36].

Another possible mechanism is that in diabetic wound conditions, cells undergo phagocytosis and produce a large number of proteinases and ROS molecules. Even though ROS molecules contribute to wound healing, in diabetic wound conditions, there will be an uncontrolled production of ROS by auto-oxidation of glucose and glycosylation of scavenging enzymes and depletion of low molecular antioxidant, resulting in oxidative stress [14]. The MDA level is the indicator for ROS generation because it represents the redox reaction level in the cell. In contrast, catalase levels represent the cellular defence, as it is a natural scavenging molecule of $\mathrm{H}_{2} \mathrm{O}_{2}$.

In the present study, we observed elevated MDA levels in the control group and the lower catalase activity. Whereas in the experimental group, we observed optimised catalase and MDA levels. Similar findings were seen in Denadai et al. who treated the diabetic skin wounds of PBMT $6 \mathrm{~J} / \mathrm{cm}^{2}$ and $660 \mathrm{~nm}$, and Tatmatsu-Rocha et al. who irradiated the super pulsed $904 \mathrm{~nm}$ laser of dosage $2.39 \mathrm{~J} /$ $\mathrm{cm}^{2}[37,38]$. It should be noted that these changes were observed in wounded tissues. In contrast, our study estimated the serum levels of catalase and MDA. However, the changes observed were significant.

In diabetic wound conditions, the primary source of ROS is mitochondria. The non-thermal, photochemical reactions of the PBMT optimizes the mitochondrial redox potential of the electron transport chain, which is sensed and transmitted to the cytosol to regulate catalase activity and other enzyme activations. Therefore, PBMT can mediate cell signalling to produce antioxidant molecules to nullify the effect of ROS. Hence, it is evident that the net amount of ROS and antioxidants required for wound healing is facilitated by PBMT, a key for fibroblastic proliferation and angiogenesis in wound healing [39].

In the present study, we observed that, after the irradiation of PBMT of dosage $4 \mathrm{~J} / \mathrm{cm}^{2}$ to the experimental group, catalase levels were significantly improved, representing a better antioxidant status. In contrast, MDA levels were significantly decreased in post-PBMT to diabetes-induced neuropathic wounds. Therefore, these may serve as adjuvant markers for oxidative status in diabetic wound conditions. 


\section{Strength and Limitations}

The present study evaluates the serum levels of oxidative stress markers whose evidence can be translated into clinical research. However, the analysis of these markers in each phase of the wound healing process is not done. The histological findings were taken during the final stages of wound healing. However, it can be considered at inflammatory, proliferative, and remodelling phases for further evidence.

\section{Conclusion}

PBMT of dosage $4 \mathrm{~J} / \mathrm{cm}^{2}$ enhanced the overall wound healing dynamics in the diabetes-induced neuropathic excisional wound model. PBMT has improved the oxidative status of the wound with optimal changes in catalase and MDA levels and facilitated a faster healing process. We observed an accelerated rate of wound contraction and reduction in the mean healing time required for wound closure compared to the un-irradiated control group. In addition, PBMT also enhanced the skin epithelialization, keratinisation, and proliferation of diabetes-induced neuropathic wounds.

\section{Future Direction}

At present, in clinical practice, the management of diabetic foot ulcer and their associated complications are challenging to clinicians. Based on the present study findings, we recommend that PBMT can be one of the promising adjuvant modality in clinical practice. Based on our findings with markers of oxidative stress, may give a clear direction for the wound condition and its response to the PBMT. However, we recommend conducting further research with different doses and wavelengths.

\section{Data Availability}

The data that support the findings of this study are available from the corresponding author, GAM, upon reasonable request

Acknowledgements We would like to acknowledge the Centre for Diabetic Foot Care and Research (CDFCR), Department of Physiotherapy, Manipal College of Health Professions (MCHP), Manipal Academy of Higher Education (MAHE)-Manipal and Dr Sanjay Bharathi, Associate professor, Department of Nuclear Medicine, Manipal College of Health Professions, Manipal Academy of Higher Education-Manipal, for their all-round support

Funding Open access funding provided by Manipal Academy of Higher Education, Manipal.

\section{Compliance with Ethical Standards}

Conflict of Interest The authors declare no competing interests.

Ethical Approval The research work was conducted after obtaining permission from the Central Animal Research Facility, Kasturba Medical College, Manipal Academy of Higher Education Manipal (IAEC/KMC/95/2018).

Health and Safety All the mandatory laboratory health and safety procedures have complied within the course of conducting any experimental work reported in this paper

Publisher's note Springer Nature remains neutral with regard to jurisdictional claims in published maps and institutional affiliations.

Open Access This article is licensed under a Creative Commons Attribution 4.0 International License, which permits use, sharing, adaptation, distribution and reproduction in any medium or format, as long as you give appropriate credit to the original author(s) and the source, provide a link to the Creative Commons license, and indicate if changes were made. The images or other third party material in this article are included in the article's Creative Commons license, unless indicated otherwise in a credit line to the material. If material is not included in the article's Creative Commons license and your intended use is not permitted by statutory regulation or exceeds the permitted use, you will need to obtain permission directly from the copyright holder. To view a copy of this license, visit http://creativecommons. org/licenses/by/4.0/.

\section{References}

1. Amos, A. F., McCarty, D. J., \& Zimmet, P. (1997). The rising global burden of diabetes and its complications: estimates and projections to the year 2010. Diabetic Medicine, 14, S7-85.

2. Boulton, A. J. (2004). The diabetic foot: from art to science. The 18th Camillo Golgi lecture. Diabetologia, 47, 1343-53.

3. International Diabetes Federation. (2019). IDF Diabetes Atlas, 9th edn. International Diabetes Federation, Brussels, Belgium. https://www.diabetesatlas.org.

4. Den Dekker, A., Davis, F. M., Kunkel, S. L., \& Gallagher, K. A. (2019). Targeting epigenetic mechanisms in diabetic wound healing. Translational Research, 204, 39-50.

5. Dunnill, C., Patton, T., Brennan, J., Barrett, J., Dryden, M., Cooke, J., Leaper, D., \& Georgopoulos, N. T. (2017). Reactive oxygen species (ROS) and wound healing: the functional role of ROS and emerging ROS-modulating technologies for augmentation of the healing process. International Wound Journal, 14, 89-96.

6. Kurahashi, T., \& Fujii, J. (2015). Roles of antioxidative enzymes in wound healing. Journal of Developmental Biology, 3, 57-70.

7. Glorieux, C., \& Calderon, P. B. (2017). Catalase, a remarkable enzyme: targeting the oldest antioxidant enzyme to find a new cancer treatment approach. Biological Chemistry, 398, 1095-108.

8. Sharma I, Ahmad P. (2014). Catalase: a versatile antioxidant in plants. In Oxidative Damage to Plants. Academic Press (131-148).

9. Ayuk SM, Abrahamse H, Houreld NN. (2016). The role of matrix metalloproteinases in diabetic wound healing in relation to photobiomodulation. Journal of diabetes research. 2016, 2897656.

10. Karkada G, Maiya GA, Houreld NN, Arany P, Rao KG M, Adiga S, Kamath SU, Shetty S. (2020) Effect of photobiomodulation therapy on inflammatory cytokines in healing dynamics of diabetic wounds: a systematic review of preclinical studies. Archives of Physiology and Biochemistry. 28,1-8. 
11. Maiya, A. G., Kumar, P., \& Nayak, S. (2009). Photo-stimulatory effect of low energy helium-neon LASER irradiation on excisional diabetic wound healing dynamics in Wistar rats. Indian Journal of Dermatology, 54, 323.

12. Kaviani, A., Djavid, G. E., Ataie-Fashtami, L., Fateh, M., Ghodsi, M., Salami, M., Zand, N., Kashef, N., \& Larijani, B. (2011). A randomized clinical trial on the effect of low-level laser therapy on chronic diabetic foot wound healing: a preliminary report. Photomedicine and Laser Surgery, 29, 109-14.

13. Lubart, R., Eichler, M., Lavi, R., Friedman, H., \& Shainberg, A. (2005). Low-energy laser irradiation promotes cellular redox activity. Photomedicine and Laser Therapy, 23(1 Feb), 3-9.

14. Bhat, R. V., Udupa, E. P., Anushree, U., Sheik, S. M., \& Nayak, B. S. (2016). Evaluation of protein thiols and liver glycogen content on Streptozotocin induced diabetic rats treated with aqueous extract of Bixa Orellana leaves. International Journal of Biochemistry Research \& Review, 13(4), 1-7.

15. Yalcin, I., Megat, S., Barthas, F., Waltisperger, E., Kremer, M., Salvat, E., \& Barrot, M. (2014). The sciatic nerve cuffing model of neuropathic pain in mice. JoVE Journal of Visualized Experiments, 16, e51608.

16. Cudlip, S. A., Howe, F. A., Griffiths, J. R., \& Bell, B. A. (2002). Magnetic resonance neurography of peripheral nerve following experimental crush injury, and correlation with functional deficit. Journal of Neurosurgery, 96(4 Apr), 755-9.

17. Anju, M., Chacko, L., Chettupalli, Y., Maiya, A. G., \& Ummer, V. S. (2019). Effect of low level laser therapy on serum vitamin D and magnesium levels in patients with diabetic peripheral neuropathy-a pilot study. Diabetes \& Metabolic Syndrome: Clinical Research \& Reviews, 13, 1087-91.

18. Dowdall, T., Robinson, I., \& Meert, T. F. (2005). Comparison of five different rat models of peripheral nerve injury. Pharmacology Biochemistry and Behavior, 80, 93-108.

19. Sushma, K., Kumar, B., Sreedhara, P., Jayakrishna, N., Anne, S., Karthik, G., \& Divya, P. (2018). The role of natural medicines on wound healing: A biomechanical, histological, biochemical and molecular study. Ethiopian Journal of Health Sciences, 28, 6.

20. Gerdes, J., Lemke, H., Baisch, H. E., Wacker, H. H., Schwab, U., \& Stein, H. (1984). Cell cycle analysis of a cell proliferationassociated human nuclear antigen defined by the monoclonal antibody Ki-67. The Journal of Immunology, 133(4 Oct), 1710-5.

21. Beers, R., \& Sizer, J. W. (1952). Spectrophotometric method for measuring the breakdown of hydrogen peroxide by catalase. $J$ Biol Chem, 195, 133-40.

22. Kei, S. (1978). Serum lipid peroxide in cerebrovascular disorders determined by a new colorimetric method. Clinica Chimica Acta, 90(1 Nov), 37-43.

23. Cavanagh, P. R., Lipsky, B. A., Bradbury, A. W., \& Botek, G. (2005). Treatment for diabetic foot ulcers. Lancet, 366, 1725-1735.

24. Akbarzadeh, A., Norouzian, D., Mehrabi, M. R., Jamshidi, S. H., Farhangi, A., Verdi, A. A., Mofidian, S. M., \& Rad, B. L. (2007). Induction of diabetes by Streptozotocin in rats. Indian Journal of Clinical Biochemistry, 22(2 Sep), 60-4.

25. Bennett, G. J., \& Xie, Y. K. (1988). A peripheral mononeuropathy in rat that produces disorders of pain sensation like those seen in man. Pain., 33(1 Apr), 87-107.

26. Seltzer, Z., Dubner, R., \& Shir, Y. (1990). A novel behavioral model of neuropathic pain disorders produced in rats by partial sciatic nerve injury. Pain, 43, 205-18.

27. de Sousa, M. V., Kawakubo, M., Ferraresi, C., Kaippert, B., Yoshimura, E. M., \& Hamblin, M. R. (2018). Pain management using photobiomodulation: Mechanisms, location, and repeatability quantified by pain threshold and neural biomarkers in mice. Journal of Biophotonics, 11, e201700370.

28. Souza, N. H., Mesquita-Ferrari, R. A., Rodrigues, M. F., da Silva, D. F., Ribeiro, B. G., Alves, A. N., Garcia, M. P., Nunes, F. D., da Silva, Jr, E. M., França, C. M., \& Bussadori, S. K. (2018). Photobiomodulation and different macrophages phenotypes during muscle tissue repair. Journal of cellular and molecular medicine, 22(10 Oct), 4922-34.

29. Andreo L, Ribeiro BG, Alves AN, Martinelli AS, Soldera CB, Horliana AC, Bussadori SK, Fernandes KP, Mesquita-Ferrari RA. (2020). Effects of photobiomodulation with low-level laser therapy on muscle repair following a peripheral nerve injury in Wistar rats. Photochemistry and Photobiology. 96,1124-1132.

30. Bertolini, G. R., Artifon, E. L., Silva, T. D., Cunha, D. M., \& Vigo, P. R. (2011). Low-level laser therapy, at $830 \mathrm{~nm}$, for pain reduction in experimental model of rats with sciatica. Arquivos de neuro-psiquiatria, 69(2B), 356-9.

31. Kajagar, B. M., Godhi, A. S., Pandit, A., \& Khatri, S. (2012). Efficacy of low level laser therapy on wound healing in patients with chronic diabetic foot ulcers-a randomized control trial. Indian Journal of Surgery, 74(5), 359-363.

32. Mathur, R. K., Sahu, K., Saraf, S., Patheja, P., Khan, F., \& Gupta, P. K. (2017). Low-level laser therapy as an adjunct to conventional therapy in the treatment of diabetic foot ulcers. Lasers in medical science, 32(2), 275-282.

33. Lau, P., Bidin, N., Krishnan, G., AnaybBaleg, S. M., Sum, M. B., Bakhtiar, H., Nassir, Z., \& Hamid, A. (2015). Photobiostimulation effect on diabetic wound at different power density of near infrared laser. Journal of Photochemistry and Photobiology B: Biology, 151, 201-7.

34. Kilík R, Lakyová L, Sabo J, Kruzliak P, Lacjaková K, Vasilenko T, Vidová M, Longauer F, Radoňak J. (2014) Effect of equal daily doses achieved by different power densities of lowlevel laser therapy at $635 \mathrm{~nm}$ on open skin wound healing in normal and diabetic rats. BioMed Research International. 2014, 269253.

35. Lau, P. S., Bidin, N., Islam, S., Musa, N., Zakaria, N., \& Krishnan, G. (2017). Influence of low power density on wound healing in streptozotocin-induced diabetic rats. Laser Physics, 27, 055604.

36. Yasukawa, A., Hrui, H., Koyama, Y., Nagai, M., \& Takakuda, K. (2007). The effect of low reactive-level laser therapy (LLLT) with helium-neon laser on operative wound healing in a rat model. Journal of Veterinary Medical Science, 69(8), 799-806.

37. Denadai, A. S., Aydos, R. D., Silva, I. S., Olmedo, L., de Senna Cardoso, B. M., da Silva, B. A., \& de Carvalho, P. D. (2017). Acute effects of low-level laser therapy $(660 \mathrm{~nm})$ on oxidative stress levels in diabetic rats with skin wounds. $J$ Exp Therapeut Oncol, 11, 85-9.

38. Tatmatsu-Rocha, J. C., Ferraresi, C., Hamblin, M. R., Maia, F. D., do Nascimento, N. R., Driusso, P., \& Parizotto, N. A. (2016). Low-level laser therapy $(904 \mathrm{~nm})$ can increase collagen and reduce oxidative and nitrosative stress in diabetic wounded mouse skin. Journal of Photochemistry and Photobiology B: Biology, 164, 96-102.

39. Mussttaf, R. A., Jenkins, D. F., \& Jha, A. N. (2019). Assessing the impact of low level laser therapy (LLLT) on biological systems: a review. International journal of radiation biology, 95(2), $120-143$. 